\title{
Identification and expression analysis of the Broad-Complex core protein isoform 6 (BR-C Z6) gene in the giant tiger shrimp Penaeus monodon (Penaeidae: Decapoda)
}

\author{
A. Buaklin'1, S. Klinbunga ${ }^{2,3}$ and P. Mensveta ${ }^{3,4}$ \\ ${ }^{1}$ Program in Biotechnology, Faculty of Science, Chulalongkorn University, \\ Bangkok, Thailand \\ ${ }^{2}$ Aquatic Molecular Genetics and Biotechnology Laboratory, \\ Agricultural Biotechnology Research Unit, \\ National Center for Genetic Engineering and Biotechnology, \\ National Science and Technology Development Agency, \\ Pathumthani, Thailand \\ ${ }^{3}$ Center of Excellence for Marine Biotechnology, Faculty of Science, \\ Chulalongkorn University, Bangkok, Thailand \\ ${ }^{4}$ Department of Marine Science, Faculty of Science, \\ Chulalongkorn University, Bangkok, Thailand
}

Corresponding author: S. Klinbunga

E-mail: sirawut@biotec.or.th

Genet. Mol. Res. 10 (4): 2290-2306 (2011)

Received November 19, 2010

Accepted February 2, 2011

Published October 3, 2011

DOI http://dx.doi.org/10.4238/2011.October.3.6

ABSTRACT. Broad-Complex $(B R-C)$ is an early ecdysone-responsive gene encoding a family of zinc-finger transcription factors that function during metamorphosis in insects. We identified two full-length cDNAs of $B R-C$ Z6 in the giant tiger shrimp (Penaeus monodon). They were 2422 and $2060 \mathrm{bp}$ in length, containing open reading frames of 1440 and $1443 \mathrm{bp}$, corresponding to polypeptides of 479 and 480 amino acids, respectively. Tissue distribution analysis indicated that $P m B R-C$ $Z 6$ was abundantly expressed in hemocytes and ovaries in juveniles. In broodstock, $P m B R-C Z 6$ was constitutively expressed in all tissues 
examined, and the highest expression was observed in ovaries. The expression of $P m B R-C Z 6$ in ovaries was significantly greater than in testes in both juveniles and broodstock of $P$. monodon. Quantitative real-time PCR indicated that the expression level of PmBR-C Z6 was significantly down-regulated in stages II and III of ovaries in intact wild broodstock and returned to the basal level in stage IV ovaries and after spawning. In eyestalk-ablated broodstock, $P m B R-C Z 6$ was significantly up-regulated in stage IV (mature) ovaries. Moreover, the expression level of PmBR-C Z6 in vitellogenic, early cortical rod and mature (stages II-IV) ovaries of eyestalk-ablated broodstock was greater than that of the same ovarian stages in intact broodstock. In situ hybridization revealed that $P m B R-C Z 6$ transcripts were localized in oogonia and cytoplasm of previtellogenic and vitellogenic oocytes of both wild intact and eyestalkabated broodstock. The effects of 20-hydroxyecdysone on expression of PmBR-C Z6 were examined. The expression level of $P m B R-C Z 6$ in ovaries of juvenile $P$. monodon was significantly increased at $168 \mathrm{~h}$ postinjection. Taken together, these findings indicate that $P m B R-C$ Z6 plays an important role in ovarian development of $P$. monodon.

Key words: Broad-complex; Gene expression; In situ hybridization; Real-time PCR; RACE-PCR

\section{INTRODUCTION}

Ecdysteroids primarily serve as molting hormones in arthropods (Huberman, 2000; Okumura and Sakiyama, 2004). In crustaceans, ecdysteroids are synthesized by the Y-organs, secreted into the hemolymph, and distributed to target tissues for conversion into the active form, 20-hydroxyecdysone (also called crustecdysone, ecdysterone; Subramoniam, 2000). There is evidence that ecdysteroids are also synthesized in the ovaries and testes of crustaceans (Styrishave et al., 2008; Brown et al., 2009). Their production is negatively regulated by the molt-inhibiting hormone, secreted from the X-organ, and positively regulated by methyl farnesoate.

In Penaeus monodon, the predominant form of ecdysteroids in circulation is 20 -hydroxyecdysone (Kuo and Lin, 1996). The peak concentration of ecdysteroids during the $P$. monodon molting cycle coincides with stages D1 and D2 (proecdysis) followed by a rapid decline afterwards (Kuo and Lin, 1996). A similar pattern of hemolymph ecdysteroid concentration was observed in Litopenaeus vannamei (Chan, 1995). Ecdysteroid concentrations were shown to be related to both vitellogenesis and molting. Gunamalai et al. (2004) monitored the concentration of 20-hydroxyecdysone in the hemolymph and ovaries through the molting cycle of the mole crab Emerita asiatica. In Drosophila, the balance between the concentration of 20-hydroxyecdysone and juvenile hormones $(\mathrm{JH})$ seems to play a significant role in the development of the oocytes (Gilbert et al., 1998; Soller et al., 1999; Gruntenko and Rauschenbach, 2008).

Broad-Complex $(B R-C)$ is one of the ecdysyteroid-responsive genes, which is a key member of the 20-hydroxyecdysone-regulatory hierarchy that coordinates changes in gene expression during Drosophila metamorphosis (Bayer et al., 1996). Typically, the $B R-C$ gene family can be divided into 4 isoforms, namely $B R-C Z 1, Z 2, Z 3$, and $Z 4$, which share an amino- 
terminal core domain (a BTB domain), which is fused by alternative splicing of different $\mathrm{C}_{2} \mathrm{H}_{2}$ zinc-finger domains (DiBello et al., 1991; Zollman et al., 1994; Bayer et al., 1996).

Chen et al. (2004) found that the $B R-C$ gene is involved in the 20-hydroxyecdysoneregulatory hierarchy controlling vitellogenesis in the mosquito Aedes aegypti. Unlike ecdysteroid receptors (E74 and $E 75$ ), the early gene expression of $B R-C$ is activated in previtellogenic females during a JH-dependent period.

In the cockroach (Blatlella germanica), the role of $B R-C$ in embryogenesis was studied (Piulachs et al., 2010) and 6 isoforms of $B R-C(Z 1-Z 6)$ were found. The temporal expression patterns indicate that $B g B R-C$ isoforms are present throughout the embryogenesis of $B$. germanica, although with weak fluctuations. Silencing all $B g B R$ - $C$ isoforms in the embryo through parental RNAi elicits a diversity of phenotypes. These phenotypes suggest roles for $B g B R-C$ in the embryogenesis processes of $B$. germanica (Piulachs et al., 2010).

To examine the molecular involvement of the $B R-C$ gene in ovarian development of $P$. monodon, the full-length cDNA of $P m B R-C Z 6$ was isolated and characterized and reported for the first time in penaeid shrimp. The effects of eyestalk ablation and 20-hydroxyecdysone administration on expression levels of ovarian $P m B R-C Z 6$ in broodstock and juveniles were examined, respectively. Localization of $P m B R-C Z 6 \mathrm{mRNA}$ and protein in different stages of oocytes was examined by in situ hybridization (ISH).

\section{MATERIAL AND METHODS}

\section{Experimental animals and design}

Female broodstock were wild-caught from the Andaman Sea and acclimated under farm conditions for 2-3 days. The post-spawning group was immediately collected after shrimp had ovulated $(\mathrm{N}=6)$. Ovaries were dissected out from each broodstock and weighed. For the eyestalk ablation group, shrimp were acclimated for 7 days prior to unilateral eyestalk ablation. Ovaries of eyestalk-ablated shrimp were collected at 2-7 days after ablation. In addition, cultured juveniles ( 4 months old, $\mathrm{N}=6$ ) and domesticated juveniles $(6$ months old, $\mathrm{N}=5)$ and broodstock of $P$. monodon 14 months old $(\mathrm{N}=14)$ and 18 months old $(\mathrm{N}=5)$ were collected from the Broodstock Management Center, Burapha University (Chanthaburi, Thailand). The gonadosomatic index (ovarian weight/body weight X100) of each shrimp was calculated. Ovarian developmental stages were classified by conventional histology (Tan-Fermin and Pudadera, 1989; Qiu et al., 2005) and divided into previtellogenic (I, N = 10 and 4 for intact and eyestalk-ablated broodstock, respectively), vitellogenic (II, $\mathrm{N}=7$ and 6), early cortical rod (III, $\mathrm{N}=7$ and 9), and mature (IV, $\mathrm{N}=9$ and 11) stages, respectively.

In addition, commercially cultured female juveniles of $P$. monodon (average body weight of $17.56 \pm 3.46 \mathrm{~g}$ ) were acclimated in the fish tanks for 2 weeks. Five groups of juvenile shrimp were single-injected intramuscularly with 20 -hydroxyecdysone $(1 \mu \mathrm{g} / \mathrm{g}$ body weight) into the first abdominal segment of each shrimp and specimens were collected at $0,6,12,24,48$ 72,96 , and $168 \mathrm{~h}$ post-injection (hpi). Shrimp injected with $10 \%$ ethanol were also included as a control (at $0 \mathrm{~h}$ ). Ovaries of each sample were dissected out and immediately placed in liquid $\mathrm{N}_{2}$. The samples were stored at $-80^{\circ} \mathrm{C}$ prior to RNA extraction and first-strand cDNA synthesis.

For tissue distribution analysis, various tissues of a female and testes of a male juvenile and broodstock were collected, immediately placed in liquid $\mathrm{N}_{2}$ and kept at $-70^{\circ} \mathrm{C}$ until needed. 


\section{Total RNA extraction and first-strand cDNA synthesis}

Total RNA was extracted from ovaries of P. monodon using TRI Reagent (Molecular Research Center). The concentration of extracted total RNA was spectrophotometrically measured. One and a half microgram of DNase I-treated total RNA $\left(0.5 \mathrm{U} / \mu \mathrm{g}\right.$ total RNA at $37^{\circ} \mathrm{C}$ for $30 \mathrm{~min}$ ) was reverse-transcribed using an Improm-II ${ }^{\mathrm{TM}}$ Reverse Transcription System (Promega).

\section{Rapid amplification of cDNA end-polymerase chain reaction (RACE-PCR)}

Gene specific primers (5'PmBR-C Z6 and 3'PmBR-C Z6) were designed. 5'- and 3'RACE-PCR were carried out using a SMART RACE cDNA Amplification Kit following the protocol recommended by the manufacturer (BD Bioscience Clontech). The amplified fragments were electrophoretically analyzed, eluted from the gel, cloned into pGEM-T Easy vector, and sequenced. Nucleotide sequences of expressed sequence tag (EST) and 5'- and 3'RACE-PCR fragments were assembled and searched against previously deposited sequences in GenBank using Blast $N$ and Blast $X$ (Altschul et al., 1990; available at http:// ncbi.nlm.nih.gov). The $\mathrm{p} I$ value and molecular weight of the deduced PmBR-C Z6 protein were examined using ProtParam (http://www.expasy.org/tools/protparam.html). The protein domain and signal peptide in the deduced PmBR-C Z6 protein were predicted using SMART (http://smart.embl-heidelberg.de).

\section{RT-PCR and tissue distribution analysis}

Expression of PmBR-C Z6 (primers PmBR-C Z6-RT-F/R; $230 \mathrm{bp}$ ) in various tissues of female broodstock and testes of male broodstock was determined by RT-PCR. $E F-1 \alpha_{500}$ (primers EF- $1 \alpha_{500}-\mathrm{F} / \mathrm{R}$ ) was included as the positive control. The thermal profiles were $94^{\circ} \mathrm{C}$ for 3 min followed by 25 cycles $(P m B R-C Z 6)$ and 23 cycles $\left(E F-1 \alpha_{500}\right)$ of denaturation at $94^{\circ} \mathrm{C}$ for $30 \mathrm{~s}$, annealing at $55^{\circ} \mathrm{C}$ for $45 \mathrm{~s}$ and extension at $72^{\circ} \mathrm{C}$ for $1 \mathrm{~min}$. The final extension was carried out at $72^{\circ} \mathrm{C}$ for $7 \mathrm{~min}$. The amplicon was electrophoretically analyzed on $1.5 \%$ agarose gels and visualized with a UV transilluminator after ethidium bromide staining (Sambrook and Russell, 2001).

\section{Quantitative real-time PCR}

Standard curves representing $10^{3}-10^{8}$ copies of $P m B R-C$ Z6 in triplicate (primers PmBR-C Z6-qRT-F/R; $244 \mathrm{bp}$ ) and the internal control, $E F-1 \alpha_{214}$ (primers EF-1 $\alpha_{214}$-F/R; Table 1), were constructed. PmBR-C Z6 and the internal control, $E F-1 \alpha_{214}$, in ovaries of each shrimp were amplified in a $10-\mu \mathrm{L}$ reaction volume containing $5 \mu \mathrm{L} 2 \mathrm{X}$ LightCycler 480 SYBR Green I Master (Roche), 100 (PmBR-C Z6) or $1\left(E F-1 \alpha_{214}\right)$ ng first-strand cDNA template, and 0.2 or $0.3 \mu \mathrm{M}$ each of respective gene-specific primers. The thermal profile for quantitative real-time PCR was $95^{\circ} \mathrm{C}$ for $10 \mathrm{~min}$ followed by 40 cycles of $95^{\circ} \mathrm{C}$ for $30 \mathrm{~s}, 53^{\circ}$ $(P m B R-C Z 6)$ or $58^{\circ} \mathrm{C}\left(E F-1 \alpha_{214}\right)$ for $30 \mathrm{~s}$ and $72^{\circ} \mathrm{C}$ for $30 \mathrm{~s}$. Real-time PCR of each specimen was carried out in duplicate. The relative expression level (copy number of PmBR-C $Z 6$ and that of $E F-1 \alpha$ ) between shrimp with different stages of ovarian development was statistically tested using ANOVA $(\mathrm{P}<0.05)$. 


\section{In situ hybridization}

Ovaries of intact and eyestalk-ablated P. monodon broodstock were fixed in 4\% paraformaldehyde prepared in $0.1 \%$ phosphate-buffered saline (PBS, pH 7.2) overnight at $4^{\circ} \mathrm{C}$. The fixed ovarian tissue was washed four times with PBS at room temperature and stored in $70 \%$ ethanol at $-20^{\circ} \mathrm{C}$ until used. Conventional paraffin sections $(5 \mu \mathrm{M})$ were prepared. The sense and antisense cRNA probes were synthesized from a PCR product using primers PmBRC Z6-ISH-F/R (Table 1). PCR was carried out in a $25-\mu \mathrm{L}$ reaction volume containing $10 \mathrm{ng}$ recombinant plasmid containing the complete open reading frame (ORF) of PmBR-C Z6 as the template. PCR was initially performed by predenaturation at $94^{\circ} \mathrm{C}$ for 2 min followed by 30 cycles of denaturation at $94^{\circ} \mathrm{C}$ for $30 \mathrm{~s}$, annealing at $60^{\circ} \mathrm{C}$ for $30 \mathrm{~s}$ and at $72^{\circ} \mathrm{C}$ for $1 \mathrm{~min}$. The PCR product was purified using a MinElute PCR purification kit (Qiagen). The cRNA probe was synthesized with a DIG RNA Labeling kit (Roche) using the protocol recommended by the manufacturer. The synthesized probes were purified using an RNeasy ${ }^{\circledR}$ MinElute ${ }^{\circledR}$ Cleanup kit (QiaGen). The amount of cRNA probes was roughly estimated by dot blot analysis. Tissue sections were dewaxed with xylene and dehydrated in absolute ethanol. The sections were prehybridized with $2 \mathrm{X}$ SSC containing $50 \%$ deionized formamide, $1 \mu \mathrm{g} / \mu \mathrm{L}$ yeast tRNA, $1 \mu \mathrm{g} /$ $\mu \mathrm{L}$ salmon sperm DNA, $1 \mu \mathrm{g} / \mu \mathrm{L}$ BSA, and $10 \%(\mathrm{w} / \mathrm{v})$ dextran sulfate at $50^{\circ} \mathrm{C}$ for $30 \mathrm{~min}$ and hybridized with either the sense or antisense probe in the prehybridization solution overnight at $50^{\circ} \mathrm{C}$. After hybridization, the tissue sections were washed twice with $4 \mathrm{X} \mathrm{SSC}$ for $5 \mathrm{~min}$ each and once with $2 \mathrm{X} \mathrm{SSC}$ containing $50 \%(\mathrm{v} / \mathrm{v})$ formamide for $20 \mathrm{~min}$ at $50^{\circ} \mathrm{C}$. The sections were immersed in prewarmed RNase A buffer $(0.5 \mathrm{M} \mathrm{NaCl}, 10 \mathrm{mM}$ Tris- $\mathrm{HCl}, \mathrm{pH} 8.0,1 \mathrm{mM}$ EDTA) at $37^{\circ} \mathrm{C}$ for $30 \mathrm{~min}$ and treated with RNase $\mathrm{A}(10 \mu \mathrm{g} / \mathrm{mL})$ at $37^{\circ} \mathrm{C}$ for $30 \mathrm{~min}$. Tissue sections were washed four times with RNase A buffer $\left(37^{\circ} \mathrm{C}, 10 \mathrm{~min}\right.$ each) and twice with $2 \mathrm{X}$ $\operatorname{SSC}\left(50^{\circ} \mathrm{C}, 15 \mathrm{~min}\right.$ each). High-stringent washing was carried out twice in $0.2 \mathrm{X} \mathrm{SSC}$ at $50^{\circ} \mathrm{C}$ for 20 min each. The positive hybridization signals were detected with the DIG Wash and Block Buffer kit (Roche) (Qiu and Yamano, 2005).

\begin{tabular}{|c|c|}
\hline Primer & Primer sequence \\
\hline \multicolumn{2}{|l|}{ RACE-PCR } \\
\hline 5' PmBR-C Z6 & R: 5'-TGATCGGACCACGTGCGAACCAG-3' \\
\hline 3' PmBR-C Z6 & F: 5'-GCCACCAACCGCTCACGCATG-3' \\
\hline \multicolumn{2}{|l|}{ RT-PCR } \\
\hline PmBR-C Z6-RT-F & F: 5'-ACGCTCACCTCCGCCCAGTC-3' \\
\hline PmBR-C Z6-RT-R & R: 5'-AGTGCCCACATTTGCCGCATTAT-3' \\
\hline $\mathrm{EF}-1 \alpha_{500}-\mathrm{F}$ & F: 5'-ATGGTTGTCAACTTTGCCCC-3' \\
\hline $\mathrm{EF}-1 \alpha_{500}-\mathrm{R}$ & R: 5'-TTGACCTCCTTGATCACACC-3' \\
\hline \multicolumn{2}{|l|}{ Quantitative real-time PCR } \\
\hline PmBR-C Z6-qRT-F & F: 5'-CGCAAAAGGCCACCAGAATCG-3' \\
\hline PmBR-C Z6-qRT-R & R: 5'-TCTGTGACTGTTCATCGCTGTTG-3' \\
\hline $\mathrm{EF}-1 \alpha_{214}-\mathrm{F}$ & F: 5'-TCCGTCTTCCCCTTCAGGACGTC-3' \\
\hline $\mathrm{EF}-1 \alpha_{214}-\mathrm{R}$ & R: 5'-CTTTACAGACACGTTCTTCACGTTG-3' \\
\hline \multicolumn{2}{|l|}{ In situ hybridization } \\
\hline PmBR-C Z6-ISH-F* & F: 5'-TAATACGACTCACTATAGGGGGAAGATTATATCCTGCACACA-3' \\
\hline PmBR-C Z6-ISH-R* & R: 5'-ATTTAGGTGACACTATAGAACTGTGACTGTTCATCGCTGTTG-3' \\
\hline
\end{tabular}




\section{RESULTS}

\section{Isolation and sequence analysis of the full-length cDNA of PmBR-C Z6}

The partial nucleotide sequence of PmBR-C Z6 was initially obtained from EST analysis of the ovarian cDNA library of $P$. monodon (Preechaphol et al., 2007). This EST significantly matches the $B R-C Z 6$ gene of the European honey bee, Apis mellifera ( $E$-value $=1 \mathrm{e}$ $110)$. Both $5^{\prime}$ and $3^{\prime}$ RACE-PCR of this gene homologue was further carried out. The positive amplification products of 158 and 1800 (3'RACE-PCR fragment 1) and 1437 (3'RACE-PCR fragment 2) bp in size were obtained. Nucleotide sequences of RACE-PCR fragments and the original EST were assembled. Two types of the full-length cDNAs of $P m B R-C Z 6$ were found (called PmBR-C Z6-1 and PmBR-C Z6-2; GenBank accession Nos. JN638739 and JN638740, respectively). They were 2422 and $2060 \mathrm{bp}$ in length, containing ORFs of 1440 and 1443 bp, corresponding to the polypeptides of 479 and 480 amino acids, respectively (Figure 1). The calculated $\mathrm{p} I$ and molecular mass of the deduced proteins were 5.54 and $53.64 \mathrm{kDa}$ and 5.46 and $53.88 \mathrm{kDa}$, respectively. Both deduced proteins contained a BTB domain at positions 31-126 $(E$-value $=4.14 \mathrm{e}-22)$ and 4 zinc finger $(\mathrm{ZnF}) \mathrm{C}_{2} \mathrm{H}_{2}$ domains (Figure 2). $P m B R-C$ Z6-1 and PmBR-C Z6-2 significantly matched the Broad-Complex core protein isoform 6 of Harpegnathos saltator ( $E$-value $=3 \mathrm{e}-31$ and $4 \mathrm{e}-31$, GenBank accession No. EFN83955). Sequence polymorphism was found including an indel at the amino acid position 248 owing to a tri-nucleotide repeat and 5 amino acid substitutions (positions 190, 203, 204, 440, and 470 where S, H, S, G, and L in PmBR-C Z6-1 were replaced by P, R, N, E, and P in PmBR-C Z6-2, respectively) within the deduced proteins.

\section{RT-PCR and tissue expression analysis of PmBR-C Z6}

Tissue distribution analysis indicated that $P m B R-C Z 6$ was abundantly expressed in hemocytes and ovaries of cultured juveniles. A lower level of expression was observed in the hepatopancreas, stomach, lymphoid organs, and plepopods of a female and testes of a male juvenile $P$. monodon. In intact wild broodstock, $P m B R-C Z 6$ was constitutively expressed in all tissues examined, and the most abundant expression was observed in ovaries (Figure 3). The expression of PmBR-C Z6 in ovaries was significantly greater than that in testes of both juveniles and broodstock of $P$. monodon $(\mathrm{N}=4$ for each group; $\mathrm{P}<0.05)$ (Figure 4).

\section{Expression levels of $P m B R-C Z 6 \mathrm{mRNA}$ during ovarian development of $P$. monodon}

Quantitative real-time PCR revealed that the expression levels of PmBR-C Z6 in ovaries of juveniles and stage I ovaries of broodstock were comparable. PmBR-C Z6 was significantly down-regulated in stages II and III of ovaries in intact wild broodstock $(\mathrm{P}<0.05)$ and returned to the basal level in stage IV ovaries and after spawning. In eyestalk-ablated broodstock, its expression level in stage IV (mature ovaries) was significantly greater than that in stage I (previtellogenic) and II (vitellogenic) ovaries $(\mathrm{P}<0.05)$. The expression level of $P m B R-C Z 6$ in vitellogenic, early cortical rod and mature (II-IV) ovaries of eyestalk-ablated broodstock was greater than that of the same stages of ovaries in intact broodstock $(\mathrm{P}<0.05)$ (Figure 5).

In addition, the expression of $P m B R-C Z 6$ in ovaries of domesticated shrimp was also examined. Its expression level in ovaries of 6-month-old juveniles and 14- and 18-month-old domesticated broodstock was not significantly different $(\mathrm{P}>0.05)$ (Figure 6). 
A

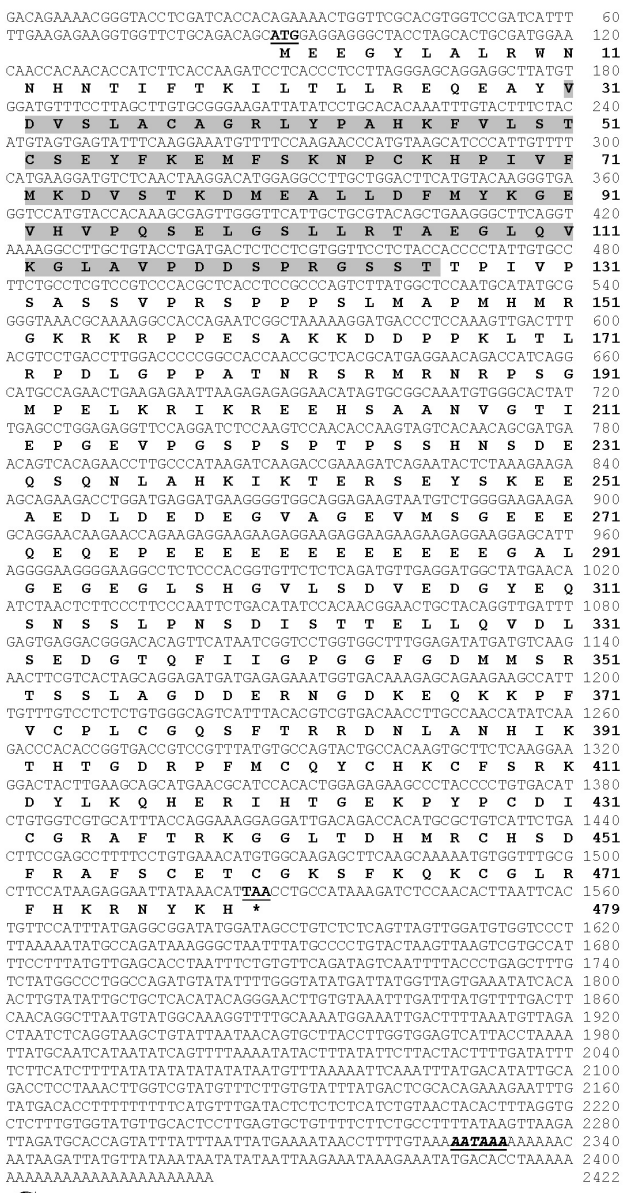

B

GACAGAAARCGGGTACCTCGATTCACCACAGAAAACTEGTTCGCACGTGGTCCGATCATTTT GO

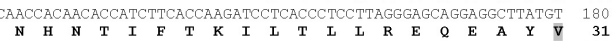

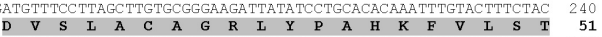

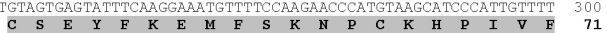

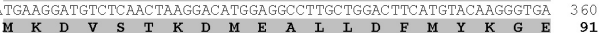

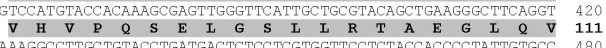

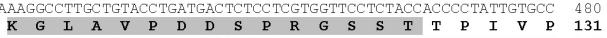

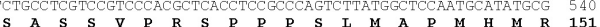

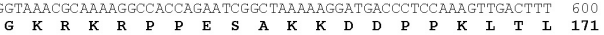

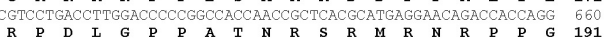

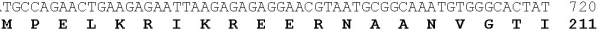

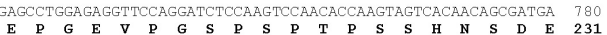
AGTCACAGAACCTTGCCCATAAGATCARGACCGAAAGATCA GAATACTCTAAAGAAGA 840

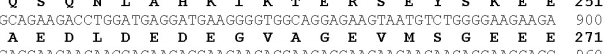

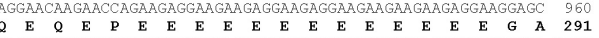

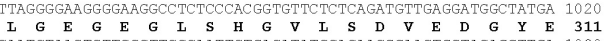

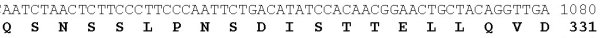

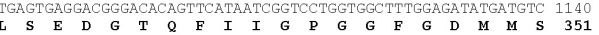
GAACTTCGTCACTAGCAGGAGATGATGAGAGAAATGGTGACAAAGAGCAGAAGAAGCC 1200

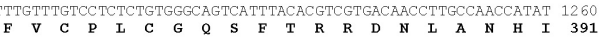

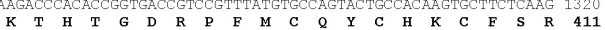
$\mathbf{K} \mathbf{Y} \mathbf{K}, \mathbf{Q}$

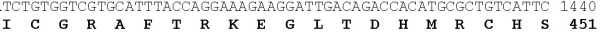

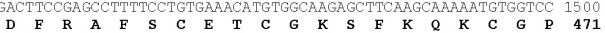

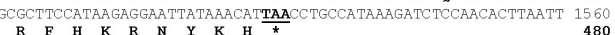
CACTGTTCCATTTATGAGGCGGA TATGGATAGCCTGTCTCTCAGTTAGTTGGATGTGGTC 1620 CCTTTAAAAATATGCCAGATA.A.GGGCTAATTTIATGCCCCTGTACTARGTTAAGTCGTGC 1680 ATM ACAACTTGTATATTGCTGCTCACATACAGGGAACTTGTGTAAATTTGATTTATAGTTTTGA 1800 CTTCAACAGGCTTAATGTATGGCAAAGGTTPTGCAAARTGGAAATT GACTTTTTAAATGTT 1920 AGATTAATCTCAGGTAAGCTGTATTAATAACAGTGCTTACCTTGGTGGAGTCATTACCTA 1980 A.ATTATGCAATCATAATATCAGTT TPAAAATATACTTTA TATTCTTACTTAAAAAAAAA 2040
C

PIMBR-C 26-1 MEEGYLALRWNNHNTI ITTKILTLIREOEAYVDVSLACAGRLYPAHKEVLSTCSEY YREME

MTER-C 26-2 MEEGYIALRWNNHNTI FTKILTLIREQEAYVDVSLACAGRIYPAHKEVLSTCSEYFKEME

PMBR-C $26-1$ SKNPCKHPIVFMKDVSTKDMEALIDEMYYGGVHVPQSELGSLIRTAEGLQVKGIAVPDDS

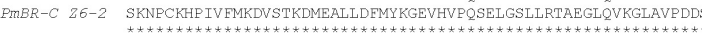

EMBR-C $26-1$ PRGSSTTPIVPSASSVPRSPPPSLMAPMHMRGKRKRPPESAKKDDPPKLTLREDLGPPAT

EMBRR-C 26-2 ERGSSTTEIVPSASSVPRSPPPSIMAEMHMRGKRKRPPESAKKDDPPKLTLRPDLGPPAT

FMBRR-C $26-1$ NRSRMRNRPS SMPELKRIKREEHSAANVGTIEPGEVPGSPSPTPSSHNSDEQSQNLAHK

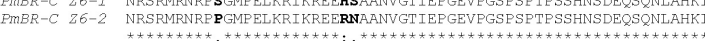

FMBR-C 26-1 KTERSEYSKEEAEDIDEDEGVAGEVMSGEEEQEQEPEEEEEEEEEEEE-GALGEGEGLSH

FMRR-C $26-2$ KTERSEYSKEEAEDLDEDEGVAGEVMSGEEEQEQEPEEEEEEEEEEEEEETGALGEGEGLSH

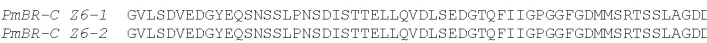

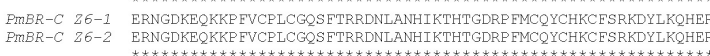

PMBR-C Z6-1 IHTGEKPYPCDICGRAFTRKGGLTDHMRCHSDFRAFSCETCGKSEKQKCGLRFHKRNYKH

EMBRR-C $26-2$ IHTGEKPYPCDICGRAFTRKEGLTDHMRCHSDFRAFSCETCGKSEKQKCGPRFHKRNYK

Figure 1. The full-length cDNA and deduced amino acids of PmBR-C Z6-1 (A) and PmBR-C Z6-2 (B). The start and stop codons are boldfaced and underlined. The polyA additional signal (AATAAA) is boldfaced, italicized and underlined. A BTB domain (positions 31-126) in both types of the deduced PmBR-C Z6 is highlighted. Pairwise sequence alignment of $P m B R-C Z 6-1$ and $P m B R-C Z 6-2(\mathbf{C})$ is illustrated.

Genetics and Molecular Research 10 (4): 2290-2306 (2011)

CFUNPEC-RP www.funpecrp.com.br 
A

PmBR-C Z6-1

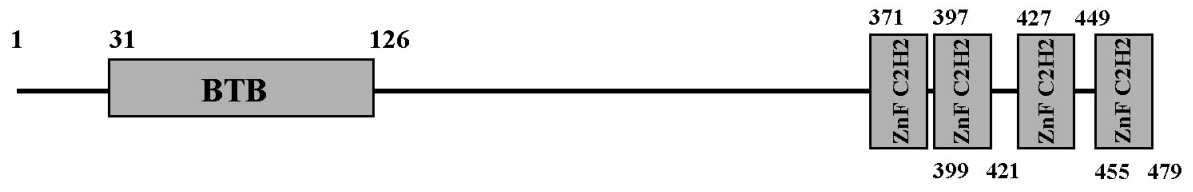

B

PmBR-C Z6-2

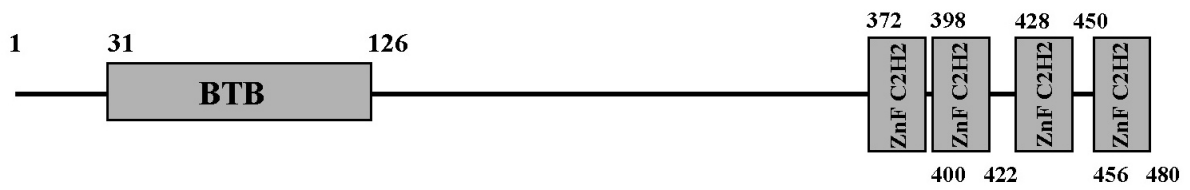

Figure 2. Schematic diagrams representing a BTB and $4 \mathrm{ZnF} \mathrm{C}_{2} \mathrm{H}_{2}$ domains in the deduced PmBR-C Z6-1 (A) and PmBR-C Z6-2 (B) proteins.

A

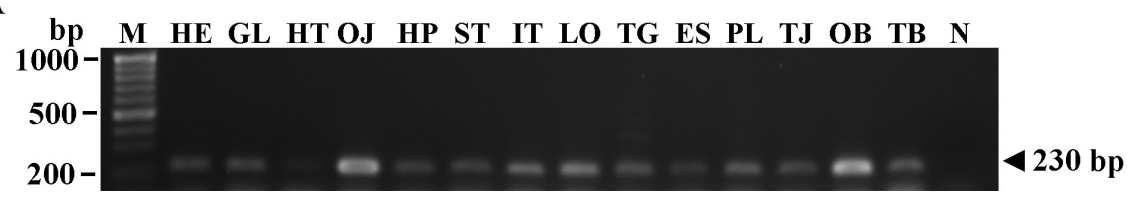

B

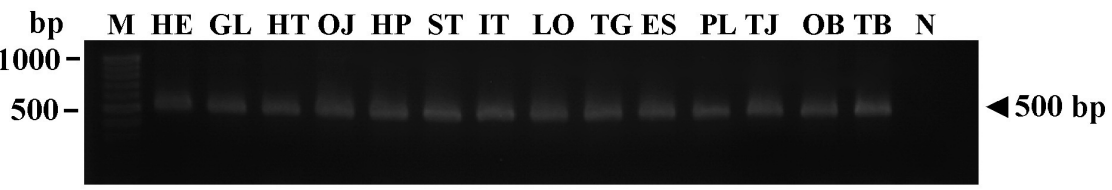

C

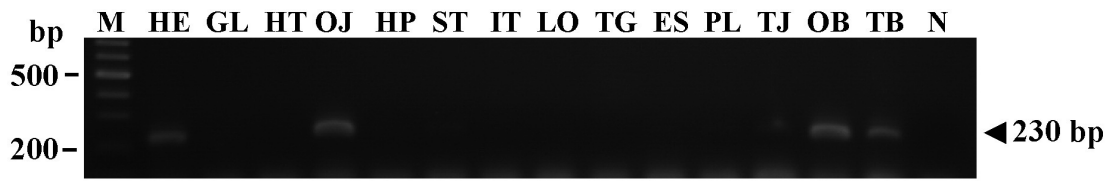

D

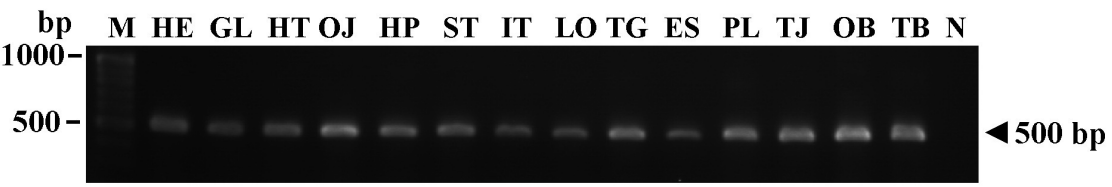

Figure 3. Tissue expression analysis of $P m B R-C Z 6(\mathbf{A}$ and $\mathbf{C})$ and $E F-1 \alpha(\mathbf{B}$ and $\mathbf{D})$ in various tissues of female $(\mathrm{HE}=$ hemocytes, $\mathrm{GL}=$ gills, $\mathrm{HT}=$ heart, $\mathrm{OJ}=$ ovaries of a juvenile, HP = hepatopancreas, $\mathrm{ST}=$ stomach, IT $=$ intestine, $\mathrm{LO}=$ lymphoid organs, $\mathrm{TG}=$ thoracic ganglion, $\mathrm{ES}=$ eyestalk, $\mathrm{PL}=$ pleopods, $\mathrm{OB}=$ ovaries of a broodstock) and testes of male (TJ and $\mathrm{TB}=$ testes of a juvenile and broodstock, respectively) broodstock (A and $\mathrm{B})$ and juveniles (C and D) of Penaeus monodon. Lanes $M$ represent a 100-bp DNA marker; Lanes $N$ represent a negative control (without the cDNA template). 

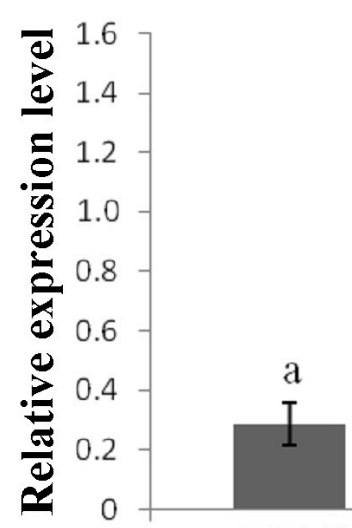

a

\section{TT-J}

Figure 4. The relative expression levels of $P m B R-C Z 6$ in testes of cultured juveniles (TT-J) and wild broodstock (TT-B) and ovaries of cultured juveniles (OV-J) and wild broodstock (OV-B) of Penaeus monodon analyzed by RT-PCR ( $\mathrm{N}=4$ for each group). Each histogram corresponds to a particular ovarian stage. The same letters above histograms reveal non-significant differences between groups of samples $(\mathrm{P}>0.05)$.

\section{Localization of PmBR-C Z6 transcript}

The cellular localization of $P m B R-C Z 6$ transcripts in ovaries of $P$. monodon broodstock was determined by ISH. The antisense $P m B R-C Z 6$ probe gave a positive signal in oogonia and cytoplasm of previtellogenic and vitellogenic oocytes in different stages of ovaries of both intact broodstock (Figure 7) and eyestalk-ablated broodstock (data not shown).

\section{Effects of 20-hydroxyecdysone administration on transcription of $P m B R-C Z 6$ in ovaries of $P$. monodon juveniles}

The effects of 20-hydroxyecdysone administration ( $1 \mu \mathrm{g} / \mathrm{g}$ body weight) on expression of $P m B R-C Z 6$ in ovaries of juvenile $P$. monodon females were examined at $6,12,24$, $48,72,96$, and $168 \mathrm{~h}$ after administration. A late response effect of 20-hydroxyecdysone on expression of PmBR-C Z6 was observed at 168 hpi (Figure 8).

\section{DISCUSSION}

\section{Characterization and primary structure of $P m B R-C Z 6$}

Closing the life cycle of cultured $P$. monodon is crucial to the sustainability of the shrimp industry. However, poor reproductive maturation of captive females and low quality of spermatozoa of captive males have limited the potential of genetic improvement, which in turn, resulted in remarkably slow domestication and selective breeding programs of $P$. monodon (Withyachumnarnkul et al., 1998; Preechaphol et al., 2007). Understanding the role of various genes during ovarian and oocyte development of $P$. monodon may lead to the possible ways to effectively induce ovarian maturation in this economically important species. 
A

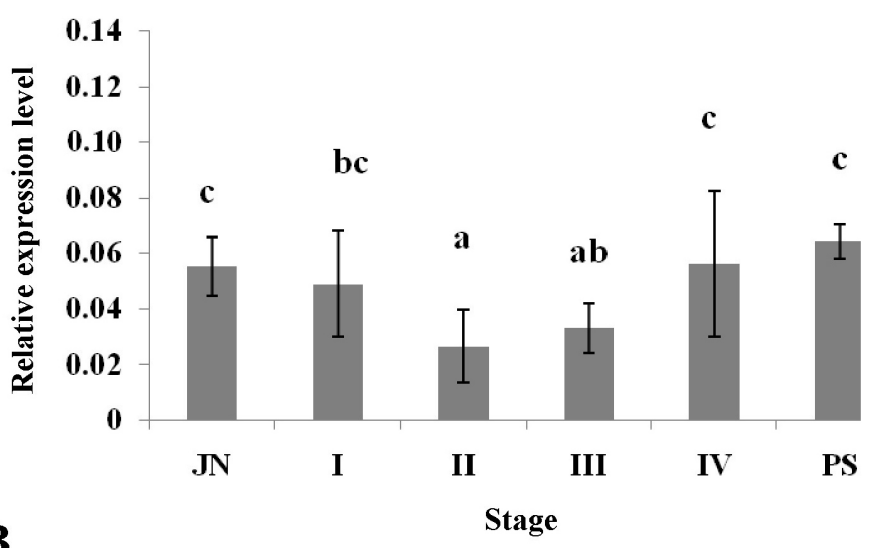

B

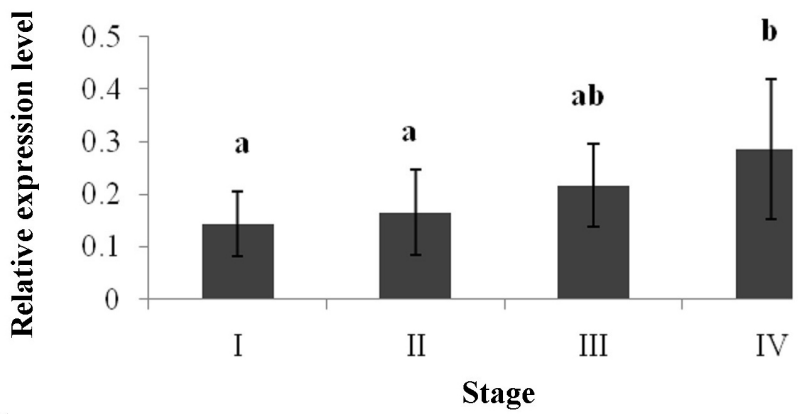

C

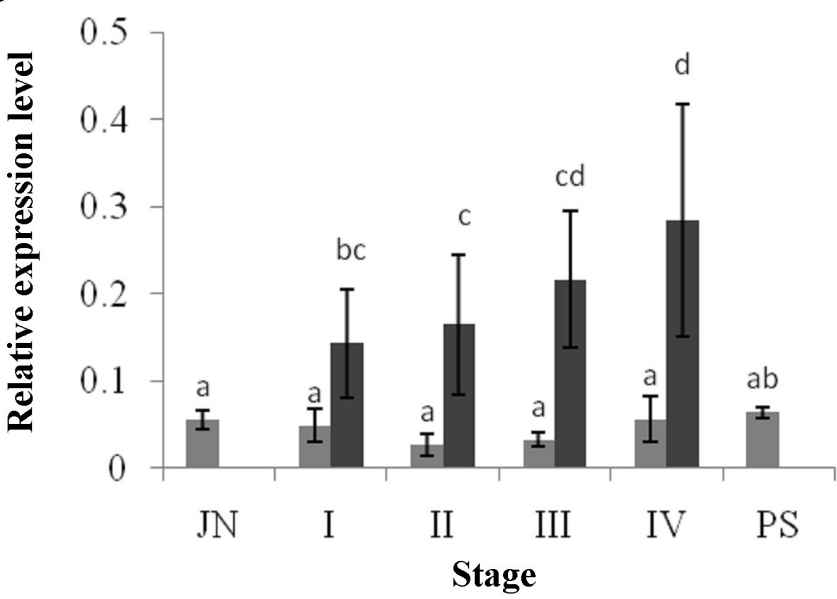

Intact

broodstock

Eyestalk-

ablated

broodstock

Figure 5. Histograms showing relative expression levels of $P m B R-C Z 6$ during ovarian development of intact (A) and unilateral eyestalk-ablated (B) Penaeus monodon broodstock analyzed by quantitative real-time PCR. Data of both intact and eyestalk-ablated broodstock were also analyzed together $(\mathbf{C})$. Each histogram corresponds to a particular ovarian stage. The same letters above histograms reveal non-significant differences between groups of samples $(\mathrm{P}>0.05)$. JN = cultured juveniles, $\mathrm{I}=$ previtellogenic; $\mathrm{II}=$ vitellogenic; $\mathrm{III}=$ early cortical rod; $\mathrm{IV}=$ mature ovaries of broodstock; PS = ovaries of intact post-spawning broodstock. 


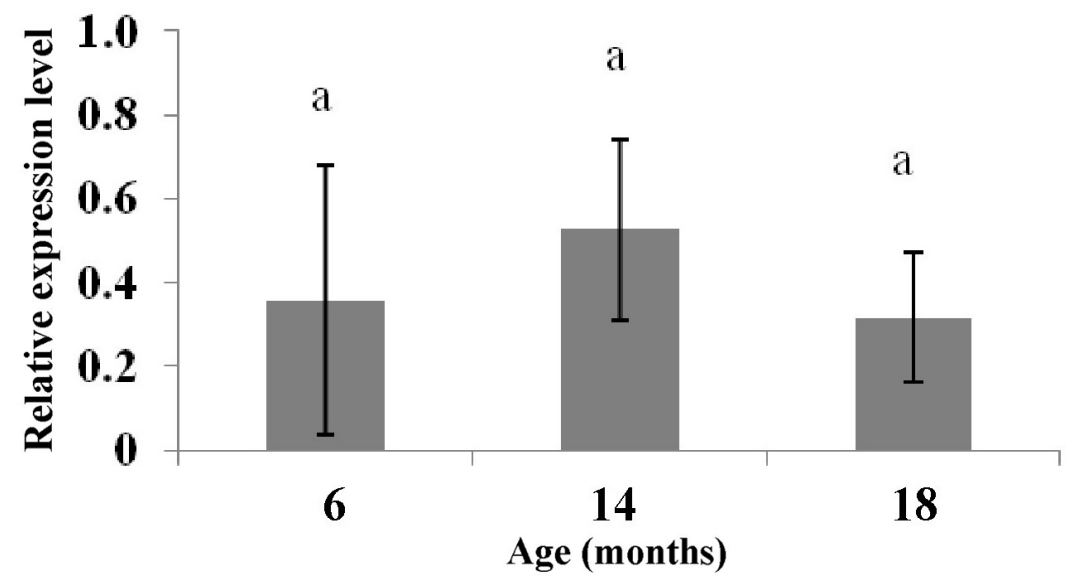

Figure 6. Histograms showing the relative expression levels of $P m B R-C Z 6$ in ovaries of domesticated juveniles (6 months old) and broodstock (14, and 18 months old) Penaeus monodon analyzed by quantitative real-time PCR. Each histogram corresponds to a particular ovarian stage. The same letters indicate that the expression levels were not significantly different $(\mathrm{P}>0.05)$.

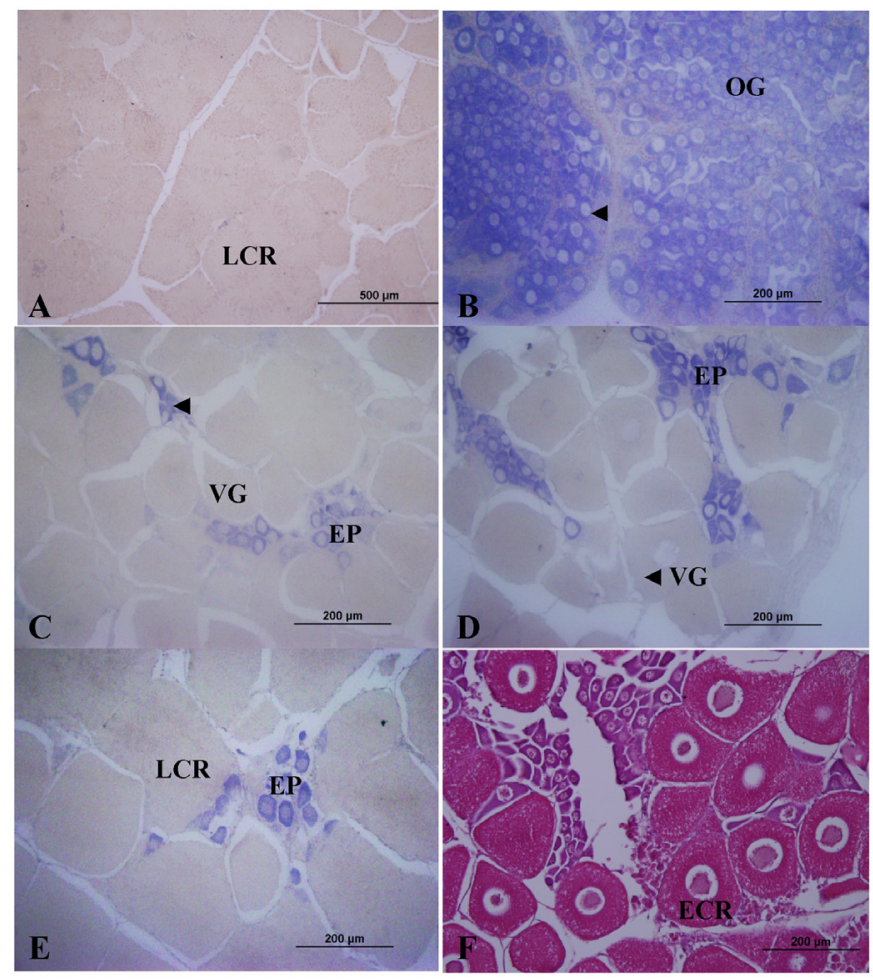

Figure 7. Localization of $P m B R-C Z 6$ transcript during ovarian development of intact Penaeus monodon broodstock visualized by in situ hybridization using the sense (A) and antisense (B-E) cRNA probes. Conventional hematoxylin/ eosin staining was carried out for identification of oocyte stages $(\mathbf{F})$. EP = early previtellogenic oocytes; ECR = early cortical rod oocytes; $\mathrm{LCR}=$ late cortical rod oocytes; $\mathrm{OG}=$ oogonia; $\mathrm{VG}=$ vitellogenic oocytes. 


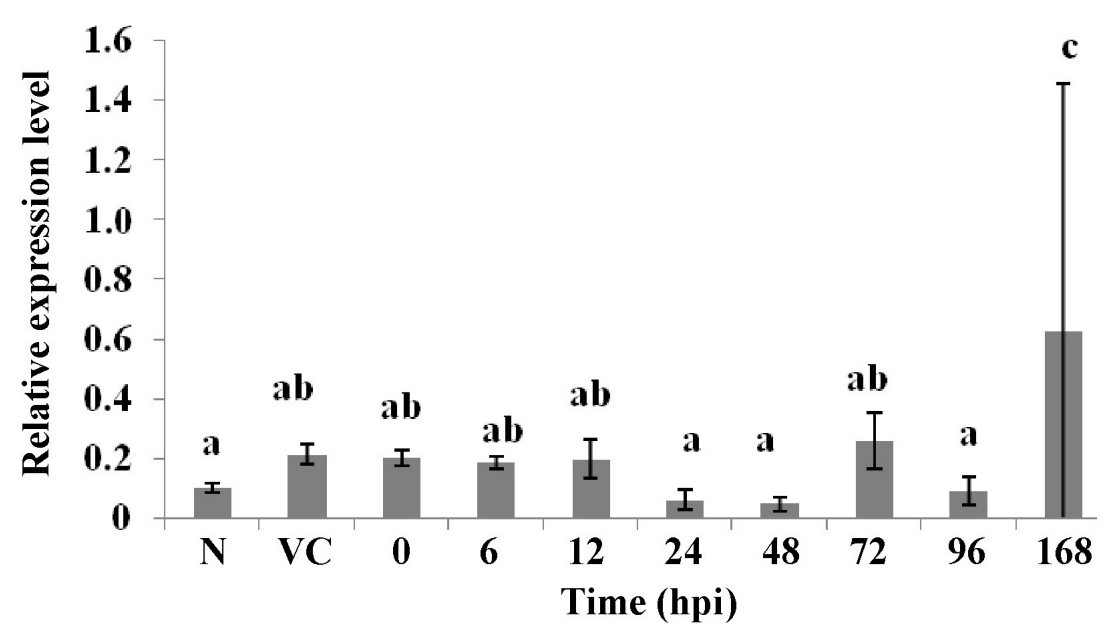

Figure 8. Time-course relative expression levels of $P m B R-C Z 6$ in ovaries of juvenile Penaeus monodon at $0,6,12$, $24,48,72,96$, and $168 \mathrm{~h}$ post-injection (hpi) of 20-hydroxyecdysone ( $1 \mu \mathrm{g} / \mathrm{g}$ body weight; $\mathrm{N}=3$ for each stage). Shrimp injected with $10 \%$ ethanol at 0 hpi were included as the vehicle control (VC). $\mathrm{N}=$ normal shrimp. The same letters indicate that the expression levels were not significantly different $(\mathrm{P}>0.05)$.

In this study, two full-length cDNAs of $P m B R-C Z 6$ were successfully characterized and reported for the first time in penaeid species. The PmBR-C Z6 proteins contain a common N-terminal Bric-a-brac-Tramtrack-Broad (BTB) domain, which is an evolutionarily conserved protein-protein interacting domain (Zollman et al., 1994) that plays critical roles in cell differentiation and development (Costoya and Pandolfi, 2001) and four zinc-finger DNA-binding domains, which function as the transcription regulator. The latter domains directly interact with cis-acting-regulatory elements in the target genes (Zhu et al., 2007). Results from sequence analysis indicated that the different types of $P m B R-C Z 6$ are allelic variants and should be transcribed from a single locus rather than generated from the alternative splicing process. High sequence similarity between $P m B R-C Z 6$ and that of other taxa (data not shown) further suggested its functional importance on the signal transduction of the 20-hydroxyecdysoneregulatory pathway in shrimp (Palli et al., 2005; Zhu et al., 2007).

\section{Expression analysis of $P m B R-C Z 6$ during ovarian development of $P$. monodon}

$B R-C$ plays key roles both in coordinating the ecdysone response among tissues and in selective activation or silencing of the downstream effector genes (Thummel, 2002). The role of $B R-C$ is well understood in Drosophila and moths (Riddiford et al., 2003), but there is limited information about its roles in adult insects.

Tissue distribution analysis revealed abundant expression of $P m B R-C Z 6$ in hemocytes and ovaries of female juveniles implying its primarily functional involvement in molting during that stage. Interestingly, more abundant expression of PmBR-C Z6 in ovaries than in other tissues was observed in P. monodon female broodstock. This suggested that $P m B R-C Z 6$ may play the alternative role in reproduction in shrimp broodstock. $P m B R-C Z 6$ was more abundantly expressed in ovaries than testes in both juveniles and 
broodstock. Therefore, $P m B R-C Z 6$ may play a more important role in oogenesis than in spermatogenesis of $P$. monodon.

Ovarian maturation of $P$. monodon results from rapid synthesis and accumulation of a major yolk protein (vitellin) (Meusy and Payen, 1988; Yano and Hoshino, 2006). Unilateral eyestalk ablation is used in practice to induce ovarian maturation in penaeid shrimp, but this technique leads to the eventual loss of egg quality and the death of spawners (Benzie, 1998; Okumura and Sakiyama, 2004). Therefore, predictable maturation and spawning of captive penaeid shrimp without the use of eyestalk ablation is a long-term goal for the industry (Quackenbush, 2001).

The expression level of PmBR-C Z6 fluctuated slightly during ovarian development (i.e., down-regulation in stages II and III before returning to the normal level in stage IV and after spawning) of intact broodstock. Eyestalk ablation clearly promoted the expression of PmBR-C Z6 during vitellogenesis and final maturation of ovaries compared to intact broodstock for approximately 3-6 times. This suggested that gonad-inhibiting hormone, a polypeptide hormone synthesized in the eyestalk (Treerattrakool et al., 2008), has a prominent effect on the transcription of PmBR-C Z6. Accordingly, the expression level of this gene may be used as molecular indicator for following the progression of ovarian development and the final maturation of $P$. monodon broodstock as a consequence of maturation-inducing feed (Meunpol et al., 2005) and/or exogenous hormonal administration (e.g., progesterone and 17- $\beta$-estradiol; Yano, 1987; Yano and Hoshino, 2006; Meunpol et al., 2007).

The high level of expression of PmBR-C Z6 was also observed in domesticated shrimp (6, 14 and 18 months old). The expression levels of PmBR-C Z6 in ovaries of domesticated 14-month-old broodstock seem to be increased compared to other ages of domesticated stocks, but results were not statistically significant owing to a large standard deviation within each group of shrimp samples $(\mathrm{P}>0.05)$.

The development of oocytes consists of a series of complex cellular events, in which different genes are expressed to ensure the proper development of oocytes and to store transcripts and proteins as maternal factors for early embryogenesis (Qiu et al., 2005). Recently, the full-length cDNA of progestin membrane receptor component 1 (Pgmrcl) in P. monodon was characterized. PmPgmrcl was 2015 bp in length, containing an ORF of $573 \mathrm{bp}$, corresponding to a polypeptide of 190 amino acids. Quantitative real-time PCR indicated that the expression level of PmPgmrc1 mRNA in ovaries of both intact and eyestalk-ablated broodstock was greater than that of juveniles $(\mathrm{P}<0.05)$. Like $P m B R-C Z 6$, PmPgmrcl was up-regulated in mature (stage IV) ovaries of intact broodstock $(\mathrm{P}<0.05)$. Unilateral eyestalk ablation resulted in an earlier up-regulation of PmPgmrcl as of the vitellogenic (II) ovarian stage. Moreover, the expression level of PmPgmrcl in vitellogenic, early cortical rod and mature (II-IV) ovaries of eyestalk-ablated broodstock was greater than that of the same ovarian stages in intact broodstock $(\mathrm{P}<0.05)$. PmPgmrc1 mRNA was clearly localized in the cytoplasm of follicular cells and previtellogenic and early vitellogenic oocytes. Immunohistochemistry revealed positive signals of the PmPgmrc1 protein in the follicular layers and cell membrane of follicular cells and various stages of oocytes (Preechaphol et al., 2010b).

In addition, the full-length cDNA of progesterone receptor-related protein p23 (p23), an essential component of the heat shock protein 90 (Hsp90) molecular chaperone complex with the progesterone receptor (Johnson and Toft, 1994), was recently character- 
ized in P. monodon. Pm-p23 was $1943 \mathrm{bp}$, comprising an ORF of $495 \mathrm{bp}$ corresponding to 164 amino acid residues and the 5' and 3' UTRs of 7 and $1441 \mathrm{bp}$, respectively. Quantitative real-time PCR analysis revealed that the expression levels of Pm-p23 in ovaries of both intact and eyestalk-ablated broodstock were significantly greater than that of juveniles (4-month-old shrimp) $(\mathrm{P}<0.05)$. Pm-p23 was up-regulated starting in stage II ovaries of intact and stage III ovaries of eyestalk-ablated $P$. monodon broodstock $(\mathrm{P}<0.05)$. The mRNA level of Pm-p23 after spawning was not significantly different from stage II-IV ovaries of intact broodstock $(\mathrm{P}<0.05)$. In situ hybridization indicated that $P m-p 23$ was localized in ooplasm of previtellogenic oocytes. The recombinant Pm-p23 protein was successfully expressed in vitro, and its polyclonal antibody was successfully produced. Western blot analysis indicated that the level of ovarian Pm-p23 protein peaked at the vitellogenic stage and decreased as oogenesis progressed (Preechaphol et al., 2010a).

Considering the findings of this study together with those of our previous studies, progesterone- and ecdysteroid-related genes seem to play an important role in ovarian development and maturation of $P$. monodon oocytes.

\section{Localization of $P m B R-C Z 6$ transcripts in ovaries of $P$. monodon}

In situ hybridization was used to determine the cellular localization of PmBR-CZ6 mRNAs in ovaries of wild $P$. monodon broodstock. PmBR-C Z6 was localized in oogonia and ooplasm of previtellogenic and vitellogenic oocytes in different stages of ovarian development of both intact and eyestalk-ablated broodstock. Generally, more intense signals were observed in ovaries of eyestalk-ablated broodstock than intact broodstock. This also implied the effects of eyestalk ablation on the transcription of this gene. In situ hybridization signals of PmBR-C Z6 were not observed in follicular cells and more mature (early cortical rod and mature) stage oocytes.

Contradictory results from quantitative real-time PCR and ISH on the disappearance of PmBR-C Z6-1 hybridization signals from the ooplasm in oocytes at later stages (early cortical rod and mature oocytes) may have been due to a significant increase in oocyte size as oogenesis proceeded. In addition, real-time PCR detects gene expression with much greater sensitivity than ISH. A similar circumstance was also observed in PmPgmrcl (Preechaphol et al., 2010a) and Pm-p23 (Preechaphol et al., 2010b).

\section{Effects of ecdysteroid administration on expression of $P m B R-C Z 6$ in ovaries of P. monodon}

Domestication of $P$. monodon is impeded by poor reproductive maturation of both male and female brooders in captivity (Withyachumnarnkul et al., 1998; Preechaphol et al., 2010a). Effects of hormones (e.g., progesterone and other sex steroids) and neurotransmitters (e.g., serotonin and dopamine; Fingerman, 1997) on expression of reproduction-related genes and, in turn, on ovarian development of $P$. monodon are of interest by aquaculturists and could be directly applied to the shrimp industry.

In the mosquito (A. aegypti), the 5'-regulatory region of vitellogenin contains the binding site for the ecdysone receptor (EcR)/homologue of the retinoid $\mathrm{X}$ receptor, ultraspiracle (USP), BR and ecdysteroid receptors; E74 and E75 (Kokoza et al., 2001; Chen et al., 2004; Zhu et al., 2007). The EcR/USP dimer binds to the vitellogenin promoter and acts synergistically with 
E74 to activate vitellogenin expression (Zhu et al., 2003, 2007). We hypothesized similar effects of 20-hydroxyecdysone on the stimulation of the BR-C Z6 gene in P. monodon. This should be proved when a large number of domesticated broodstock are available for the experiments.

Molecular effects of 20-hydroxyecdysone on the expression of reproduction-related genes in penaeid shrimp have not been reported. Due to the high cost ( $\sim 200 \mathrm{USD} /$ brooder) of a gravid female of $P$. monodon (Preechaphol et al., 2007), approximately 4-month-old commercially cultured shrimp were used to examine the effects of 20-hydroxyecdysone on the expression of ovarian PmBR-C Z6.

Treated juvenile shrimp showed immediate response to exogenous 20-hydroxyecdysone administration by molting within $48 \mathrm{~h}$ following the treatment in most individuals of all treatments. The expression level of PmBR-C Z6 was up-regulated at 168 hpi. Differential expression of $P m B R-C Z 6$ should have reflected long duration effects of the ecdysteroid on the expression of these genes. The molecular effects of 20-hydroxyecdysone on this expression should be further examined in both wild and domesticated broodstock to evaluate the possible use of ecdysteroids for enhancing ovarian/oocyte development in P. monodon.

In the present study, the ecdysyteroid-responsive gene of $P$. monodon was identified. The expression profile of PmBR-C Z6 in ovaries of intact and eyestalk-ablated P. monodon broodstock implied that it should contribute to ovarian development of $P$. monodon. Functionally, analysis of genes and proteins involving ovarian development can be further carried out for better understanding of the reproductive maturation of female P. monodon in captivity.

\section{ACKNOWLEDGMENTS}

Research supported by the National Center for Genetic Engineering and Biotechnology (BIOTEC), National Science and Technology Development Agency (NSTDA), Thailand, awarded to S. Klinbunga A student grant (to A. Buaklin) was awarded by Thailand Graduate Institute of Science and Technology (TGIST).

\section{REFERENCES}

Altschul SF, Gish W, Miller W, Myers EW, et al. (1990). Basic local alignment search tool. J. Mol. Biol. 215: 403-410.

Bayer CA, Holley B and Fristrom JW (1996). A switch in Broad-Complex zinc-finger isoform expression is regulated posttranscriptionally during the metamorphosis of Drosophila imaginal discs. Dev. Biol. 177: 1-14.

Benzie JAH (1998). Penaeid genetics and biotechnology. Aquaculture 164: 23-47.

Brown MR, Sieglaff DH and Rees HH (2009). Gonadal ecdysteroidogenesis in arthropoda: occurrence and regulation. Annu. Rev. Entomol. 54: 105-125.

Chan S-M (1995). Possible roles of 20-hydroxyecdysone in the control of ovary maturation in the white shrimp Penaeus vannamei (Crustacea: Decapoda). Comp. Biochem. Physiol. C Toxicol. Pharmacol. 112: 51-59.

Chen L, Zhu J, Sun G and Raikhel AS (2004). The early gene Broad is involved in the ecdysteroid hierarchy governing vitellogenesis of the mosquito Aedes aegypti. J. Mol. Endocrinol. 33: 743-761.

Costoya JA and Pandolfi PP (2001). The role of promyelocytic leukemia zinc finger and promyelocytic leukemia in leukemogenesis and development. Curr. Opin. Hematol. 8: 212-217.

DiBello PR, Withers DA, Bayer CA, Fristrom JW, et al. (1991). The Drosophila Broad-Complex encodes a family of related proteins containing zinc fingers. Genetics 129: 385-397.

Fingerman M (1997). Roles of neurotransmitters in regulating reproductive hormone release and gonadal maturation in decapod crustaceans. Inver. Reprod. Dev. 31: 47-54.

Gilbert LI, Serafin RB, Watkins NL and Richard DS (1998). Ecdysteroids regulate yolk protein uptake by Drosophila melanogaster oocytes. J. Insect Physiol. 44: 637-644.

Gruntenko NE and Rauschenbach IY (2008). Interplay of JH, 20E and biogenic amines under normal and stress conditions 
and its effect on reproduction. J. Insect Physiol. 54: 902-908.

Gunamalai V, Kirubagaran R and Subramoniam T (2004). Hormonal coordination of molting and female reproduction by ecdysteroids in the mole crab Emerita asiatica (Milne Edwards). Gen. Comp. Endocrinol. 138: 128-138.

Johnson JL and Toft DO (1994). A novel chaperone complex for steroid receptors involving heat shock proteins, immunophilins, and p23. J. Biol. Chem. 269: 24989-24993.

Huberman A (2000). Shrimp endocrinology. A review. Aquaculture 191: 191-208.

Kokoza VA, Martin D, Mienaltowski MJ, Ahmed A, et al. (2001). Transcriptional regulation of the mosquito vitellogenin gene via a blood meal-triggered cascade. Gene 274: 47-65.

Kuo CM and Lin WW (1996). Changes in morphological characteristics and ecdysteroids during the molting cycle of tiger shrimp, Penaeus monodon Fabricus. Zool. Stud. 35: 118-127.

Meunpol O, Meejing P and Piyatiratitivorakul P (2005). Maturation diet based on fatty acid content for male Penaeus monodon (Fabricius) broodstock. Aquacult. Res. 36: 1216-1225.

Meunpol O, Iam-Pai S, Suthikrai W and Piyatiratitivorakul S (2007). Identification of progesterone and $17 \alpha$-hydroxyprogesterone in polychaetes (Perinereis sp.) and the effects of hormone extracts on penaeid oocyte development in vitro. Aquaculture 270: 485-492.

Meusy JJ and Payen GG (1988). Female reproduction in malacostracan Crustacea. Zool. Sci. 5: 217-265.

Okumura T and Sakiyama K (2004). Hemolymph levels of vertebrate-type steroid hormones in female kuruma prawn Marsupenaeus japonicus (Crustacea: Decapoda: Penaeidae) during natural reproductive cycle and induced ovarian development by eyestalk ablation. Fish. Sci. 70: 372-380.

Palli SR, Hormann RE, Schlattner U and Lezzi M (2005). Ecdysteroid receptors and their applications in agriculture and medicine. Vitam. Horm. 73: 59-100.

Piulachs MD, Pagone V and Belles X (2010). Key roles of the Broad-Complex gene in insect embryogenesis. Insect Biochem. Mol. Biol. 40: 468-475.

Preechaphol R, Leelatanawit R, Sittikankeaw K, Klinbunga S, et al. (2007). Expressed sequence tag analysis for identification and characterization of sex-related genes in the giant tiger shrimp Penaeus monodon. J. Biochem. Mol. Biol. 40: 501-510.

Preechaphol R, Klinbunga S, Ponza P and Menasveta P (2010a). Isolation and characterization of progesterone receptorrelated protein p23 (Pm-p23) differentially expressed during ovarian development of the giant tiger shrimp Penaeus monodon. Aquaculture 308: S75-S82.

Preechaphol R, Klinbunga S, Yamano K and Menasveta P (2010b). Molecular cloning and expression of progestin membrane receptor component 1 (Pgmrc1) of the giant tiger shrimp Penaeus monodon. Gen. Comp. Endocrinol. 168: 440-449.

Qiu GF and Yamano K (2005). Three forms of cyclin B transcripts in the ovary of the kuruma prawn Marsupenaeus japonicus: their molecular characterizations and expression profiles during oogenesis. Comp. Biochem. Physiol. B. Biochem. Mol. Biol. 141: 186-195.

Qiu GF, Yamano K and Unuma T (2005). Cathepsin C transcripts are differentially expressed in the final stages of oocyte maturation in kuruma prawn Marsupenaeus japonicus. Comp. Biochem. Physiol. B. Biochem. Mol. Biol. 140: 171-181.

Quackenbush LS (2001). Yolk synthesis in the marine shrimp, Penaeus vanname. Am. Zool. 41: 458-464.

Riddiford LM, Hiruma K, Zhou X and Nelson CA (2003). Insights into the molecular basis of the hormonal control of molting and metamorphosis from Manduca sexta and Drosophila melanogaster. Insect Biochem. Mol. Biol. 33: 1327-1338.

Sambrook J and Russell DW (2001). Molecular Cloning: A Laboratory Manual. Cold Spring Harbor Laboratory Press, New York.

Soller M, Bownes M and Kubli E (1999). Control of oocyte maturation in sexually mature Drosophila females. Dev. Biol. 208: 337-351.

Styrishave B, Lund T and Andersen O (2008). Ecdysteroids in female shore crabs Carcinus maenas during the moulting cycle and oocyte development. J. Mar. Biol. Assoc. 88: 575-581.

Subramoniam T (2000). Crustacean ecdysteriods in reproduction and embryogenesis. Comp. Biochem. Physiol. C. Toxicol. Pharmacol. 125: 135-156.

Tan-Fermin JD and Pudadera RA (1989). Ovarian maturation stages of the wild giant tiger prawn, Penaeus monodon Fabricius. Aquaculture 77: 229-242.

Thummel CS (2002). Ecdysone-regulated puff genes 2000. Insect Biochem. Mol. Biol. 32: 113-120.

Treerattrakool S, Panyim S, Chan SM, Withyachumnarnkul B, et al. (2008). Molecular characterization of gonad-inhibiting hormone of Penaeus monodon and elucidation of its inhibitory role in vitellogenin expression by RNA interference. FEBS J. 275: 970-980.

Withyachumnarnkul B, Boonsaeng V, Flegel TW, Panyim S, et al. (1998). Domestication and Selective Breeding of 
Penaeus monodon in Thailand. In: Proceedings to the Special Session on Advances in Shrimp Biotechnology (Flegel T, ed.). The Fifth Asian Fisheries Forum: International Conference on Fisheries and Food Security Beyond the Year 2000, Thailand, 73-77.

Yano I (1987). Effect of 17- $\alpha-\mathrm{OH}-$ progesterone on vitellogenin secretion in kuruma prawn, Penaeus japonicus. Aquaculture 61: 46-57.

Yano I and Hoshino R (2006). Effects of 17 beta-estradiol on the vitellogenin synthesis and oocyte development in the ovary of kuruma prawn (Marsupenaeus japonicus). Comp. Biochem. Physiol. A. Mol. Integr. Physiol. 144: 18-23.

Zhu J, Miura K, Chen L and Raikhel AS (2003). Cyclicity of mosquito vitellogenic ecdysteroid-mediated signaling is modulated by alternative dimerization of the RXR homologue Ultraspiracle. Proc. Natl. Acad. Sci. U. S. A. 100: 544-549.

Zhu J, Chen L and Raikhel AS (2007). Distinct roles of Broad isoforms in regulation of the 20-hydroxyecdysone effector gene, Vitellogenin, in the mosquito Aedes aegypti. Mol. Cell Endocrinol. 267: 97-105.

Zollman S, Godt D, Prive GG, Couderc JL, et al. (1994). The BTB domain, found primarily in zinc finger proteins, defines an evolutionarily conserved family that includes several developmentally regulated genes in Drosophila. Proc. Natl. Acad. Sci. U. S. A. 91: 10717-10721. 